\title{
Роль вузов в реализации возможностей и сдерживании угроз инновационному развитию экономики - мнения экспертов
}

\author{
Ю. И. Трещевский ${ }^{1}$ Е. А. Руднев ${ }^{2}$, И. С. Иванов ${ }^{3 凶}$ \\ 1,2,3 Воронежский государственный университет, Университетская пл., 1, \\ 394018, Воронеж, Российская Федерация
}

Для цитирования: Трещевский Ю. И., Руднев Е. А., Иванов И. С. Роль вузов в реализации возможностей и сдерживании угроз инновационному развитию экономики - мнения экспертов // Вестник Воронежского государственного университета. Серия: Экономика и управление. 2020. T. 3. С. 60-69.DOI: 10.17308/econ.2020.3/3105

\begin{abstract}
Цель. Определение роли вузов в реализации возможностей и сдерживании угроз развитию инновационной экономики, связанной с подготовкой кадров и научно-практическим сотрудничеством. Выявление особенностей взглядов различных институциональных групп общества на перспективы инновационной экономики.

Методология. Основу исследования составил экспертный метод. Всего в оценке возможностей и угроз приняли участие 106 экспертов, объединенных в четыре институциональные группы: представители банков, бизнес реального сектора экономики, органы власти, профессорско-преподавательский состав вузов. Оценка производилась по сформулированным экспертами 18 возможностям и 19 угрозам, из состава которых выбраны позиции, на которые оказывает влияние состояние кадрового обеспечения и взаимодействие вузов с организациями реального сектора экономики. Для обработки результатов использовался аппарат нечеткой логики.

Результаты. В составе возможностей развития инновационной экономики две непосредственно связаны с подготовкой квалифицированных кадров и семь - с научно-практическим сотрудничеством вузов, НИИ, предприятий реального сектора экономики. В составе 19 угроз - четыре обусловлены недостаточной квалификацией, слабой государственной поддержкой специалистов. Позиции экспертов внутри групп в большинстве случаев достаточно согласованы. Между оценками различных групп заметны существенные различия. Все группы экспертов оценили угрозы выше, чем возможности, что можно считать пессимистичным отношением к перспективам развития инновационной экономики. В числе возможностей наиболее значимыми признаны: государственная поддержка талантливых ученых и специалистов в области научной, научно-технологической и инновационной деятельности; государственная поддержка малых инновационных предприятий. В составе угроз: низкий уровень бюджетного финансирования академической науки и высшей школы; отсутствие необходимой правовой базы, защищающей собственников результатов интеллектуальной деятельности; отставание высшей школы в подготовке кадров, обладающих компетенциями, адекватными требованиям инновационной экономики; «утечка мозгов» действующих и потенциальных разработчиков технологических и продуктовых новаций.
\end{abstract}

Ключевые слова: инновационное развитие, возможности, угрозы, экспертная оценка.

\section{Введение}

Развитие инновационной экономики в регионах России является в настоящее время наиболее перспективным направлением ее движения. На инновационное технико-технологическое

() Трещевский Ю. И., Руднев Е. А., Иванов И. С. Вестник ВГУ. Серия: Экономика и управление. 2020. № 3. C. 60-69. развитие ориентируют нормативные документы федерального и регионального уровней ${ }^{1}$.

${ }^{1}$ Постановление Правительства РФ от 15 апреля 2014 г. № 328 «Об утверждении государственной программы Российской Федерации «Развитие промышленности и повышение ее конкурентоспособности» с изменениями и дополнениями от 31 марта 2017 г., 10 февраля, 30 марта, 1 октября, 14 декабря 2018 г., 29 марта 2019 г. URL: https://base.garant.ru/70643464/c97cd9b59d9 7ee89f8842c374b081d6f/\#block_7000 
Роль вузов в реализации возможностей и сдерживании угроз инновационному развитию экономики...

В теоретических исследованиях основания для развития инновационных процессов раскрыты в работах Н. А. Кулагиной [7], В. В. Курченкова [8], И. Е. Рисина [11], Н. А. Серебряковой [13], Н. В. Сироткиной [14], Д. Ю. Трещевского [19].

Результаты инновационного развития социально-экономических систем различного уровня зависят от широко круга факторов - от технико-технологических до институциональных, что отмечают в своих работах А. В. Барков, Я. С. Гришина [1], А. К. Дегтярев, К. В. Воденко [2], Д.А. Ендовицкий [3; 18], О. А. Жукова [4], Г. А. Ключарев, М. С. Попов [5], А. П. Латкин, В. Г. Кривошапов [9], М. В. Литовкин, В. В. Майорова, Л. М. Никитина [20], Г. М. Мурзагалина [10], М. Ю. Саенко [12], Г. В. Суровицкая [15], М. Б. Табачникова [16], Е. В. Франк [17] и другие исследователи.

В статье представлены результаты относительно мало исследованного аспекта проблемы инновационного развития - оценка возможностей и угроз в данной сфере экспертным сообществом. В составе сформулированных экспертами возможностей и угроз выбраны для исследования аспекты, связанные с двумя формами влияния вузов на инновационное развитие экономики подготовкой кадров и взаимодействием с организациями реального сектора экономики.

\section{Методология исследования}

Для оценки возможностей и угроз развитию инновационной экономики использован экс- пертный метод. Общее количество экспертов, принявших участие в оценке, - 106, анкетирование произведено по группам экспертов, в составе которых - представители банков, бизнес реального сектора экономики, органы власти, профессорско-преподавательский состав вузов.

Состав возможностей и угроз сформулирован поэтапно экспертами, представляющими все вышеуказанные институциональные группы. Общее количество сформулированных возможностей - 18 (нумерация использованная в таблицах, приведена в приложении).

Обработка результатов анкетирования произведена с использованием аппарата нечеткой логики, методические аспекты которой приняты по работам Л. К. Конышевой, Д. М. Назарова [6]. Расчеты обобщающих показателей, отражающих силу влияния и вероятность реализации события (возможности или угрозы), и их интерпретация приняты по методике, предложенной М. Б. Табачниковой [16].

\section{Результаты}

Для анализа приняты возможности и угрозы: возможности в сфере подготовки квалифицированных кадров - представлены возможностями 8 и 9; возможности в сфере научно-практического сотрудничества - представлены возможностями 4, 5, 7, 11-14; угрозы в сфере подготовки и сохранения кадрового потенциала - представлены угрозами 1, 11, 12, 14 (табл. 1-4).

Т а бли ц а 1

Оценка возможностей и угроз развитию инновационной экономики со стороны системы образования представителями банковского сектора

\begin{tabular}{|c|c|c|c|c|c|}
\hline \multirow[b]{2}{*}{ Возможности } & \multicolumn{2}{|c|}{ Средние значения } & \multicolumn{2}{|c|}{ Индексы нечеткости } & \multirow[b]{2}{*}{$\begin{array}{c}\text { Обобщающий } \\
\text { показатель }\end{array}$} \\
\hline & $\begin{array}{c}\text { Вероятность } \\
\text { реализации } \\
\text { возможности } \\
\end{array}$ & $\begin{array}{l}\text { Сила влияния } \\
\text { возможности }\end{array}$ & $\begin{array}{c}\text { Вероятность } \\
\text { реализации } \\
\text { возможности }\end{array}$ & $\begin{array}{l}\text { Сила влияния } \\
\text { возможности }\end{array}$ & \\
\hline \multicolumn{6}{|c|}{ Возможности в сфере подготовки квалифицированных кадров } \\
\hline 8 & 4,18 & 4,41 & 0,03 & 0,07 & 18,39 \\
\hline 9 & 4,00 & 4,53 & 0,04 & 0,06 & 18,07 \\
\hline $\begin{array}{c}\text { Средние значе- } \\
\text { ния по группе }\end{array}$ & 4,09 & 4,47 & 0,03 & 0,06 & 18,23 \\
\hline \multicolumn{6}{|c|}{ Возможности в сфере научного сотрудничества } \\
\hline 4 & 3,12 & 3,24 & 0,10 & 0,06 & 10,02 \\
\hline 5 & 3,59 & 4,00 & 0,10 & 0,10 & 14,21 \\
\hline 7 & 3,18 & 3,94 & 0,10 & 0,04 & 12,47 \\
\hline 11 & 3,24 & 3,76 & 0,08 & 0,12 & 12,07 \\
\hline 12 & 3,82 & 4,00 & 0,09 & 0,04 & 15,24 \\
\hline 13 & 3,82 & 4,29 & 0,06 & 0,05 & 16,37 \\
\hline 14 & 3,12 & 3,53 & 0,10 & 0,09 & 10,91 \\
\hline $\begin{array}{c}\text { Средние значе- } \\
\text { ния по группе }\end{array}$ & 3,41 & 3,82 & 0,09 & 0,07 & 13,04 \\
\hline \multicolumn{6}{|c|}{ Угрозы в сфере подготовки и сохранения кадрового потенциала } \\
\hline 1 & 4,33 & 4,29 & 0,08 & 0,07 & 18,51 \\
\hline 11 & 3,56 & 4,35 & 0,10 & 0,03 & 15,43 \\
\hline 12 & 3,78 & 4,65 & 0,06 & 0,04 & 17,52 \\
\hline 14 & 4,22 & 4,71 & 0,06 & 0,04 & 19,82 \\
\hline $\begin{array}{c}\text { Средние значе- } \\
\text { ния по группе }\end{array}$ & 3,97 & 4,50 & 0,07 & 0,05 & 17,82 \\
\hline
\end{tabular}


Анализ данных, представленных в табл. 1, позволяет сделать следующие выводы.

Представители банковского сектора в целом наиболее высоко оценивают возможности, связанные с подготовкой квалифицированных кадров, особенно расширение подготовки и переподготовки специалистов, владеющих компетенциями, адекватными требованиям инновационной экономики.

Показательно, что и угрозы в этой сфере оценены почти так же высоко. При этом наивысший балл получила «утечка мозгов» действующих и потенциальных разработчиков технологических и продуктовых новаций.

Возможности, связанные с научно-практическим сотрудничеством, оценены представителями банковского сектора в основном на низком уровне (от 10 до 14 баллов значений обобщающего показателя). Средними значениями можно признать отставание высшей школы в подготовке кадров, обладающих компетенциями, адекватными требованиям инновационной экономики; внешние санк- ции, блокирующие передачу новых технологий, освоенных в зарубежных странах, российским компаниям.

Средние величины силы влияния возможностей и угроз в большинстве случаев выше, чем возможности их реализации, что свидетельствует о пессимистичном отношении представителей банковской сферы к системам образования и научно-практического сотрудничества. Исключение составляет низкий уровень бюджетного финансирования академической науки и высшей школы, оцененный практически одинаково как по силе влияния, так и по вероятности реализации угрозы.

Индексы нечеткости, значения которых в основном не выше 0,1 , свидетельствуют о достаточной согласованности мнений экспертной группы. Только в отношении открытия и развития технопарков с акселерационной программой и производственными центрами коллективного использования оценки неоднозначно (индекс нечеткости 0,12).

Т а бли ц а 2

Оценка возможностей и угроз развитию инновационной экономики со стороны системы образования представителями бизнеса

\begin{tabular}{|c|c|c|c|c|c|}
\hline \multirow[b]{2}{*}{ Возможности } & \multicolumn{2}{|c|}{ Средние значения } & \multicolumn{2}{|c|}{ Индексы нечеткости } & \multirow[b]{2}{*}{$\begin{array}{c}\text { Обобщающий } \\
\text { показатель }\end{array}$} \\
\hline & $\begin{array}{c}\text { Вероятность } \\
\text { реализации } \\
\text { возможности }\end{array}$ & $\begin{array}{l}\text { Сила влияния } \\
\text { возможности }\end{array}$ & $\begin{array}{c}\text { Вероятность } \\
\text { реализации } \\
\text { возможности }\end{array}$ & $\begin{array}{l}\text { Сила влияния } \\
\text { возможности }\end{array}$ & \\
\hline \multicolumn{6}{|c|}{ Возможности в сфере подготовки квалифицированных кадров } \\
\hline 8 & 3,70 & 4,76 & 0,05 & 0,03 & 17,58 \\
\hline 9 & 4,57 & 4,72 & 0,05 & 0,04 & 21,53 \\
\hline $\begin{array}{c}\text { Средние значе- } \\
\text { ния по группе }\end{array}$ & 4,13 & 4,74 & 0,05 & 0,04 & 19,55 \\
\hline \multicolumn{6}{|c|}{ Возможности в сфере научного сотрудничества } \\
\hline 4 & 3,63 & 4,38 & 0,10 & 0,04 & 15,85 \\
\hline 5 & 4,13 & 4,62 & 0,09 & 0,05 & 19,02 \\
\hline 7 & 3,93 & 4,48 & 0,07 & 0,07 & 17,55 \\
\hline 11 & 3,57 & 4,28 & 0,03 & 0,04 & 15,23 \\
\hline 12 & 4,40 & 4,90 & 0,03 & 0,01 & 21,54 \\
\hline 13 & 4,20 & 4,62 & 0,07 & 0,05 & 19,34 \\
\hline 14 & 3,77 & 4,48 & 0,06 & 0,05 & 16,84 \\
\hline $\begin{array}{c}\text { Средние значе- } \\
\text { ния по группе }\end{array}$ & 3,95 & 4,54 & 0,06 & 0,04 & 17,91 \\
\hline \multicolumn{6}{|c|}{ Угрозы в сфере подготовки и сохранения кадрового потенциала } \\
\hline 1 & 4,03 & 4,45 & 0,09 & 0,08 & 17,83 \\
\hline 11 & 4,55 & 4,61 & 0,06 & 0,04 & 20,93 \\
\hline 12 & 4,42 & 4,55 & 0,07 & 0,04 & 20,05 \\
\hline 14 & 4,52 & 4,26 & 0,06 & 0,06 & 19,17 \\
\hline $\begin{array}{c}\text { Средние значе- } \\
\text { ния по группе }\end{array}$ & 4,38 & 4,47 & 0,07 & 0,05 & 19,49 \\
\hline
\end{tabular}


Роль вузов в реализации возможностей и сдерживании угроз инновационному развитию экономики...

Данные, представленные в табл. 2, позволяют сделать вывод, что представители бизнеса более «чувствительны» к предполагаемым возможностям и угрозам - обобщающие показатели их оценки в большинстве случаев выше, чем у представителей банковской сферы.

В составе возможностей наиболее оптимистичные ожидания связаны с государственной поддержкой талантливых ученых и специалистов в области научной, научно-технологической и инновационной деятельности.

Среди угроз наиболее значимыми признаны: отсутствие необходимой правовой базы, защищающей собственников результатов интеллектуальной деятельности и отставание высшей школы в подготовке кадров, обладающих компетенциями, адекватными требованиям инновационной экономики.

Возможности, связанные с научным сотрудничеством, представители бизнеса, как и банковской сферы, оценили ниже, чем «кадровые». Наиболее низкую оценку получили: становление рынка объектов интеллектуальной собственности; открытие и развитие технопарков с акселерационной программой и производственными центрами коллективного использования; формирование межвузовских научно-исследовательских центров для создания и коммерциализации инновационных разработок.

Как и представители банковской сферы, и возможности, и угрозы оценены выше по силе влияния, чем по вероятности реализации. Исключение - «утечка мозгов» действующих и потенциальных разработчиков технологических и продуктовых новаций, вероятность этой угрозы оценена выше, чем сила влияния.

Следует отметить гораздо более высокую согласованность мнений представителей бизнеса, чем банковской сферы - индексы нечеткости колеблются, в основном, в диапазоне $0,03-0,07$.

Т а бли ц а 3

Оценка возможностей и угроз развитию инновационной экономики со стороны системы образования представителями органов власти

\begin{tabular}{|c|c|c|c|c|c|}
\hline \multirow[b]{2}{*}{ Возможности } & \multicolumn{2}{|c|}{ Средние значения } & \multicolumn{2}{|c|}{ Индексы нечеткости } & \multirow[b]{2}{*}{$\begin{array}{c}\text { Обобщающий } \\
\text { показатель }\end{array}$} \\
\hline & $\begin{array}{c}\text { Вероятность } \\
\text { реализации } \\
\text { возможности }\end{array}$ & $\begin{array}{l}\text { Сила влияния } \\
\text { возможности }\end{array}$ & $\begin{array}{c}\text { Вероятность } \\
\text { реализации } \\
\text { возможности }\end{array}$ & $\begin{array}{l}\text { Сила влияния } \\
\text { возможности }\end{array}$ & \\
\hline \multicolumn{6}{|c|}{ Возможности в сфере подготовки квалифицированных кадров } \\
\hline 8 & 3,91 & 4,00 & 0,06 & 0,07 & 15,57 \\
\hline 9 & 4,27 & 4,73 & 0,07 & 0,05 & 20,13 \\
\hline $\begin{array}{c}\text { Средние значе- } \\
\text { ния по группе }\end{array}$ & 4,09 & 4,36 & 0,07 & 0,06 & 17,85 \\
\hline \multicolumn{6}{|c|}{ Возможности в сфере научного сотрудничества } \\
\hline 4 & 3,90 & 3,80 & 0,10 & 0,06 & 14,72 \\
\hline 5 & 3,64 & 3,64 & 0,05 & 0,05 & 13,19 \\
\hline 7 & 3,36 & 4,00 & 0,02 & 0,02 & 13,45 \\
\hline 11 & 3,45 & 3,73 & 0,04 & 0,07 & 12,83 \\
\hline 12 & 4,09 & 4,27 & 0,08 & 0,07 & 17,38 \\
\hline 13 & 3,27 & 3,64 & 0,05 & 0,09 & 11,85 \\
\hline 14 & 3,55 & 3,73 & 0,07 & 0,05 & 13,17 \\
\hline $\begin{array}{c}\text { Средние значе- } \\
\text { ния по группе }\end{array}$ & 3,61 & 3,83 & 0,06 & 0,06 & 13,80 \\
\hline \multicolumn{6}{|c|}{ Угрозы в сфере подготовки и сохранения кадрового потенцииала } \\
\hline 1 & 3,82 & 4,73 & 0,04 & 0,07 & 18,00 \\
\hline 11 & 3,45 & 4,09 & 0,09 & 0,05 & 14,07 \\
\hline 12 & 3,73 & 3,64 & 0,11 & 0,09 & 13,43 \\
\hline 14 & 4,64 & 4,91 & 0,00 & 0,05 & 22,76 \\
\hline $\begin{array}{c}\text { Средние значе- } \\
\text { ния по группе } \\
\end{array}$ & 3,91 & 4,34 & 0,06 & 0,06 & 17,06 \\
\hline
\end{tabular}


Анализ данных, представленных в табл. 3, позволяет отметить особенности восприятия возможностей и угроз представителями органов власти. Прежде всего обращает на себя внимание достаточно низкое среднее значение обобщающего показателя возможностей в сфере подготовки квалифицированных кадров. Высоко оценена только возможность государственной поддержки талантливых исследователей и специалистов. Впрочем, данная оценка ниже, чем у представителей бизнеса.

Значения угроз в сфере подготовки и сохранения кадрового потенциала существенно различаются. Очень высоко (обобщающий показатель - 22,76 балла) оценена угроза «утечки мозгов». Довольно высока оценка негативного влияния низкого уровня бюджетного финансирования академической науки и высшей школы. Остальные угрозы оцениваются как невысокие.

Чрезвычайно интересный и даже парадоксальный результат демонстрирует оценка профессорско-преподавательским составом вузов возможностей в сфере подготовки квалифицированных кадров - она ниже, чем у всех остальных групп, причем это относится как подготовке специалистов, владеющих необходимыми компетенциями, так и к государственной поддержке талантливых ученых и специалистов в сферах научной, научно-технологической и инновационной деятельности.

Возможности, связанные с расширением научного сотрудничества вузов, НИИ, предприятий реального сектора экономики также оценены весьма низко - чуть выше, чем представителями банковской сферы. Наименьшие оценки получили проекты ГЧП с участием вузов и НИИ и межвузовские научно-исследовательские центры инновационных разработок (обобщающие показатели не достигают 11 баллов из 25 возможных).

На среднем уровне $(16,42$ и 16,32 баллов соответственно) оценены перспективы инновационного развития за счет инновационной инфраструктуры и поддержки малых инновационных предприятий.

Т а бл ц а 4

Оценка возможностей и угроз развитию инновационной экономики со стороны системы образования профессорско-преподавательским составом вузов

\begin{tabular}{|c|c|c|c|c|c|}
\hline \multirow[b]{2}{*}{ Возможности } & \multicolumn{2}{|c|}{ Средние значения } & \multicolumn{2}{|c|}{ Индексы нечеткости } & \multirow[b]{2}{*}{$\begin{array}{c}\text { Обобщающий } \\
\text { показатель }\end{array}$} \\
\hline & $\begin{array}{c}\text { Вероятность } \\
\text { реализации } \\
\text { возможности }\end{array}$ & $\begin{array}{l}\text { Сила влияния } \\
\text { возможности }\end{array}$ & $\begin{array}{c}\text { Вероятность } \\
\text { реализации } \\
\text { возможности } \\
\end{array}$ & $\begin{array}{l}\text { Сила влияния } \\
\text { возможности }\end{array}$ & \\
\hline \multicolumn{6}{|c|}{ Возможности в сфере подготовки квалифицированных кадров } \\
\hline 8 & 3,78 & 4,00 & 0,10 & 0,10 & 14,97 \\
\hline 9 & 3,44 & 4,22 & 0,08 & 0,07 & 14,45 \\
\hline $\begin{array}{c}\text { Средние значе- } \\
\text { ния по группе }\end{array}$ & 3,61 & 4,11 & 0,09 & 0,09 & 14,71 \\
\hline \multicolumn{6}{|c|}{ Возможности в сфере научного сотрудничества } \\
\hline 4 & 2,89 & 3,78 & 0,06 & 0,09 & 10,85 \\
\hline 5 & 3,63 & 4,56 & 0,09 & 0,06 & 16,42 \\
\hline 7 & 3,33 & 3,67 & 0,09 & 0,09 & 12,12 \\
\hline 11 & 3,33 & 3,78 & 0,05 & 0,10 & 12,53 \\
\hline 12 & 3,78 & 4,33 & 0,06 & 0,05 & 16,32 \\
\hline 13 & 3,33 & 4,11 & 0,09 & 0,08 & 13,61 \\
\hline 14 & 3,00 & 3,67 & 0,08 & 0,05 & 10,96 \\
\hline $\begin{array}{c}\text { Средние значе- } \\
\text { ния по группе }\end{array}$ & 3,33 & 3,98 & 0,07 & 0,07 & 13,26 \\
\hline \multicolumn{6}{|c|}{ Угрозы в сфере подготовки и сохранения кадрового потенциала } \\
\hline 1 & 4,33 & 4,78 & 0,07 & 0,08 & 20,58 \\
\hline 11 & 3,56 & 4,00 & 0,11 & 0,07 & 14,11 \\
\hline 12 & 3,78 & 3,67 & 0,03 & 0,08 & 13,82 \\
\hline 14 & 4,22 & 4,33 & 0,06 & 0,05 & 18,24 \\
\hline $\begin{array}{c}\text { Средние значе- } \\
\text { ния по группе }\end{array}$ & 3,97 & 4,19 & 0,07 & 0,07 & 16,69 \\
\hline
\end{tabular}


Роль вузов в реализации возможностей и сдерживании угроз инновационному развитию экономики...

Средняя оценка угроз существенно выше, чем возможностей. Вполне объяснимы опасения профессорско-преподавательского состава относительно негативного влияния на инновационные процессы низкого уровня бюджетного финансирования академической науки и высшей школы. Угроза получила оценку более 20 баллов. Это самый высокий балл в оценках возможностей и угроз сотрудниками вузов и самый высокий в оценках данной угрозы представителями всех четырех институциональных групп экспертов.

Как и все иные группы, сотрудники вузов оценили выше силу влияния возможностей и угроз, чем перспективы их реализации.

Степень согласованности мнений экспертов довольно высокая, в большинстве случаев индекс нечеткости колеблется в диапазоне 0,05-0,08.

Довольно значительно расходятся мнения экспертов относительно силы влияния и вероятности реализации возможностей рынка венчурных инвестиций (в обоих случаях значения индекса нечеткости 0,1). Сила влияния технопарков с акселерационной программой и производственными центрами коллективного использования оценена неоднозначно (индекс нечеткости - 0,1). Относительно вероятности реализации такой угрозы, как отсутствие правовой базы, защищающей собственников результатов интеллектуальной деятельности, мнения экспертов расходятся (индекс нечеткости - 0,11).

\section{Выводы}

В целом из сформулированных экспертами 18 возможностей развития инновационной экономики в российских регионах две непосредственно связаны с подготовкой квалифицированных кадров и семь - с интеграционными процессами, обеспечивающими взаимодействие вузов, НИИ, предприятий реального сектора экономики. В составе 19 угроз четыре обусловлены недостаточной квалификацией, слабой государственной поддержкой специалистов, владеющих необходимыми компетенциями и, как результат, -возможным их оттоком за рубеж.

Позиции экспертов, представляющих четыре институциональные группы: представители банков, бизнес реального сектора экономики, органы власти, профессорско-преподавательский состав вузов, в большинстве случаев достаточно согласованы внутри каждой группы, но значительно различаются между группами.
Особенно «чувствительны» к оценке возможностей и угроз представители бизнеса, наиболее высоко оценившие как возможности, так и угрозы.

Самая «сдержанная» группа - профессорско-преподавательский состав вузов, давший наименьшие оценки и возможностям, и угрозам.

Представители банковского сектора и органов власти в большей степени обращают внимание на кадровые аспекты развития инновационной экономики и не считают особенно важными процессы взаимодействия предприятий с вузами, НИИ, создание разного рода интеграционных объединений.

Если исходить из средних значений оценок по обобщающим показателям, учитывающим силу их влияния и вероятность реализации событий, то все группы экспертов оценили угрозы выше, чем возможности, что можно считать пессимистичным отношением к перспективам развития инновационной экономики.

Несмотря на довольно существенные различия в оценках возможностей и угроз развития инновационной экономики, можно выделить наиболее значимые из них, оцененные хотя бы одной группой на уровне выше 20 баллов.

В числе возможностей - государственная поддержка талантливых ученых и специалистов в области научной, научно-технологической и инновационной деятельности; государственная поддержка малых инновационных предприятий. В составе угроз: низкий уровень бюджетного финансирования академической науки и высшей школы; отсутствие необходимой правовой базы, защищающей собственников результатов интеллектуальной деятельности; отставание высшей школы в подготовке кадров, обладающих компетенциями, адекватными требованиям инновационной экономики; «утечка мозгов» действующих и потенциальных разработчиков технологических и продуктовых новаций.

Малозначимых возможностей и угроз, т. е. оцененных всеми группами экспертов на уровне ниже 12,5 баллов (50 \% от максимально возможной величины), нет.

\section{Конфликт интересов}

Авторы декларируют отсутствие явных и потенциальных конфликтов интересов, связанных с публикацией настоящей статьи. 


\section{Библиографический список}

1. Барков А. В., Гришина Я. С. «Университет 3.0» : правовая модель участия вуза в инновационном предпринимательстве // Вестник Балтийского федерального университета им. И. Канта. Серия: Гуманитарные и общественные науки. 2017. № 3. С. 5-15.

2. Дегтярев А. К., Воденко К. В. Вуз как социально-экономическая система инновационного типа // Гуманитарий Юга России. 2018. Т. 7, № 2. С. 109-121.

3. Ендовицкий Д. А., Коротких В. В., Воронова М. В. Конкурентоспособность российских университетов в глобальной системе высшего образования : количественный анализ // Высшее образование в России. 2020. T. 29, № 2. C. 9-26.

4. Жукова О. А. Инновационный университет и российская модернизация // Инновационное развитие профессионального образования. 2018. Т. 19, № 3. C. 26-33.

5. Ключарев Г. А., Попов М. С. Социально-экономический эффект государственной поддержки исследований и разработок // Образование и наука в России: состояние и потенциал развития. 2018. № 3. С. 553-589.

6. Конышева Л. К., Назаров Д. М. Основы теории нечетких множеств : учебное пособие. СПб. : Питер, 2011. 192 c.

7. Кулагина Н. А., Козлова Е. М. Методика исследования инновационного потенциала при разработке региональных программ социально-экономического развития // ВУЗ. ХХІ. 2015. № 1. С. 31-40.

8. Курченков В. В., Дейнега В. Г. Об основных подходах к формированию наукоемкой экономики в современной России // Бизнес. Образование. Право. 2013. № 2 (23). С. 40-45.

9. Латкин А. П., Кривошапов В. Г. Моделирование управления интеграцией вуза в национальной инновационной системе // Азимут научных исследований: экономика и управление. 2018. Т. 7, № 2 (23). С. $181-186$.

10. Мурзагалина Г. М. Университет как источник предпринимательской культуры // Экономика и предпринимательство. 2019. № 6 (107). С. 729-732.

11. Рисин И. Е., Трещевский Ю. И., Эйтингон В.Н. Ключевые задачи научно-технологической поли- тики и подходы к их решению // Вестник Воронежского государственного университета. Серия: Экономика и управление. 2014. № 2. С. 134-138.

12. Саенко М. Ю. Инновационная деятельность университетов в модернизации экономики России // Современные экономические и информационные технологии. 2018. № 2. С. 4-7.

13. Серебрякова Н. А., Грищенко Н. В. Формирование и развитие инновационного потенциала региона // Экономика. Инновации. Управление качеством. 2018. № 1 (22). С. 50a-52.

14. Сироткина Н. В., Поляков А. В., Гончаров А. Ю. Инновационная среда региона: формирование и развитие : монография. Воронеж : Научная книга, 2015. 223 c.

15. Суровицкая Г. В. Влияние опорных вузов на развитие региональных экономических и инновационных систем // Известия высших учебных заведений. Поволжский регион. Общественные науки. 2019. № 2 (50). С. 200-209.

16. Табачникова М. Б. Оценка экономического пессимизма институциональных групп региона // Регион: системы, экономика, управление. 2016. № 1 (32). C. 96-102.

17. Франк Е. В. Моделирование процесса формирования и развития инновационного потенциала опорного вуза региона // Московский экономический журнал. 2019. № 11. С. 79.

18. Endovitsky D. A., Tabachnikova M. B. \& Treshchevsky Yu. I. Analysis of the economic optimism of the institutional groups and socio-economic systems // Journal of Advanced Research in Law and Economics. 2017. Vol. VIII (6), pp. 1745-1752.

19. Treshchevskiy D. Y., Papin S. N. \& Penina E. O. Innovation Risks in the Region - Expert Analysis // Proceedings of the 2nd International Conference on Economy, Management and Entrepreneurship (ICOEME 2019). Atlantis Press, 2019. Pp. 311-315.

20. Treshchevsky Y., Nikitina L., Litovkin M. \& Mayorova $V$. Results of Innovational Activities of Russian Regions in View of the Types of Economic Culture // Russia and the European Union, Development and Perspectives. Contributions to Economics, 2017. Pp. 47-53.

E-mail: fopus@yandex.ru

ORCID: 0000-0002-3405-6227

Иванов Иван Сергеевич, студент, экономический факультет, Воронежский государственный университет, Воронеж, Российская Федерация

E-mail: if.iwan2014@yandex.ru

ORCID: 0000-0002-9626-6924

Поступила в редакцию 15.07.2020

Подписана в печать 10.09.2020 ями, Воронежский государственный университет, Воронеж, Российская Федерация 


\section{Возможности развития инновационной экономики}

1. Разработка и реализация федеральных государственных программ, обеспечивающих инновационное развитие экономики.

2. Разработка и реализация региональных государственных программ, обеспечивающих инновационное развитие экономики.

3. Расширение участия региона в реализации Национальной технологической инициативы. и НИИ.

4. Реализация проектов ГЧП с участием вузов

5. Развитие инновационной инфраструктуры (инжиниринговых центров, центров трансфера технологий, центров коллективного пользования, технологических парков).

6. Приток венчурного капитала.

7. Становление рынка объектов интеллектуальной собственности.

8. Расширение подготовки и переподготовки специалистов, владеющих компетенциями, адекватными требованиям инновационной экономики.

9. Государственная поддержка талантливых ученых и специалистов в области научной, научно-технологической и инновационной деятельности.

10. Создание и развитие инновационных кластеров.

11. Открытие и развитие технопарков с акселерационной программой и производственными центрами коллективного использования.

12. Государственная поддержка малых инновационных предприятий.

13. Создание научно-образовательных центров на основе интеграции вузов и научных организаций и их кооперации с организациями реального сектора экономики.

14. Формирование межвузовских научно-исследовательских центров для создания и коммерциализации инновационных разработок.

15. Формирование кооперации с зарубежными компаниями по внедрению технологических и продуктовых новаций, интеграция региональных производителей в международные цепочки создания стоимости.

16. Создание среды для онлайновых коммуникаций между разработчиками инноваций, бизнесом и государственными органами.

17. Реализация информационной политики, направленной на повышение престижности инновационной и научной деятельности, пропаганда инновационной культуры через средства массовой информации и интернет.

18. Снижение Центральным банком ключевой ставки.

\section{Угрозы развитию инновационной экономики}

1. Низкий уровень бюджетного финансирования академической науки и высшей школы.

2. Отсутствие у коммерческих организаций реального сектора экономики необходимых средств на финансирование проектов разработки и внедрения технологических и продуктовых новаций.

3. Отсутствие у банков достаточных стимулов для долгосрочного кредитования инновационной деятельности организаций реального сектора экономики.

4. Снижение стимулов для создания и внедрения инноваций в связи с монополизацией и огосударствлением экономики.

5. Ухудшение общей институциональной среды в России.

6. Наличие барьеров для включения российских инновационных компаний в международную производственную кооперацию.

7. Отсутствие налоговых льгот и иных преференций для кластеров и технопарков, осуществляющих инновационную деятельность.

8. Отсутствие налоговых льгот и иных преференций для технологического предпринимательства.

9. Отсутствие государственной поддержки совместных проектов вузов и индустриальных партнеров по созданию высокотехнологичных производств.

10. Отсутствие рынка венчурных инвестиций.

11. Отсутствие необходимой правовой базы, защищающей собственников результатов интеллектуальной деятельности.

12. Отставание высшей школы в подготовке кадров, обладающих компетенциями, адекватными требованиям инновационной экономики.

13. Внешние санкции, блокирующие передачу новых технологий, освоенных в зарубежных странах, российским компаниям.

14. «Утечка мозгов» действующих и потенциальных разработчиков технологических и продуктовых новаций.

15. Низкий уровень инновационной культуры населения.

16. Низкий уровень восприимчивости бизнеса к инновациям.

17. Отсутствие необходимой взаимосвязи подсистем и отдельных элементов внутри инновационной системы региона.

18. Высокие темпы инфляции.

19. Волатильность валютного рынка и, как следствие, удорожание импортного оборудования и комплектующих изделий. 


\title{
The role of universities in the realization of opportunities and curbing threats to innovative economic development - expert opinions
}

\author{
Y. I. Treschevsky ${ }^{1}$, E. A. Rudnev ${ }^{1}$ I. S. Ivanov ${ }^{1 凶}$ \\ ${ }^{1}$ Voronezh State University, University sq., 1, Voronezh, 394018, Russian Federation
}

Cite as: Treschevsky, Y. I., Rudnev, E. A., Ivanov, I. S. (2020) The role of universities in the realization of opportunities and curbing threats to innovative economic development - expert opinions. Proceedings of Voronezh State University. Series: Economics and Management. 3, 58-69. (In Russ., abstract in Eng.) DOI: 10.17308/econ.2020.3/3105

\begin{abstract}
Purpose. Defining the role of universities in realizing opportunities and containing threats to the development of an innovative economy related to training and scientific and practical cooperation. Identification of peculiarities of views of different institutional groups of society on the characteristics of innovation economy.

Methodology. The study was based on an expert method. In total, 106 experts representing four institutional groups took part in the assessment of opportunities and threats: representatives of banks, business of the real sector of the economy, authorities, faculty of universities. The evaluation is carried out on 18 possibilities formulated by experts and 19 threats from which positions are selected, which are influenced by the state of personnel provision and interaction of universities with organizations of the real sector of the economy. A fuzzy logic set was used to process the results.

Results. As part of the development opportunities of the innovative economy, two are directly related to the training of qualified personnel and seven - to the scientific and practical cooperation of universities, research institutes, enterprises of the real sector of the economy. In the composition of 19 threats - four are caused by insufficient qualification, weak state support of specialists. The positions of experts within the groups are in most cases sufficiently harmonized. There are significant differences between the estimates of different groups. All expert groups assessed threats higher than opportunities, which could be considered a pessimistic attitude to the prospects for the development of an innovative economy. Among opportunities as the most significant are recognized: the state support of talented scientists and experts in the field of scientific, scientific and technological and innovative activity; State support for small innovative enterprises. Threats include low budget funding for academic science and higher education; Lack of the necessary legal framework to protect intellectual property owners; Lagging behind in the training of personnel with competencies adequate to the requirements of an innovative economy; «Brain drain» of current and potential developers of technological and product innovations.
\end{abstract}

Key words: innovative development, opportunities, threats, expert assessment.

\section{Conflict of interest}

The authors declare the absence of obvious and potential conflicts of interest related to the publication of this article.

2. Degtyarev, A. K. \& Vodenko, K. V. (2018) [Higher education institute as an innovative socio-economic system]. Humanities of the south of Russia. 7 (2), 109121. (In Russ.)

3. Endovitsky, D. A., Korotkikh, V. V., \& Voronova, M. V. (2020). Competitiveness of Russian Universities in the Global System of Higher Education: Quantitative Analysis. Vysshee obrazovanie v Rossii [Higher Education in Russia]. 29 (2), 9-26. (In Russ., abstract in Eng.)

4. Zhukova O. A. (2018) [Innovative university and Russian modernization]. Innovative development of vocational education. 19 (3), 26-33. (In Russ.).

\section{References}

1. Barkov, A. V. \& Grishina Y. S. (2017) [3.0 University: Legislative framework for innovative entrepreneurship]. Vestnik IKBFU. Humanities and social sciences. 3, 5-15. (In Russ.)

5. Kliucharev, G. A. \& Popov M. S. (2018) [Socio-economic effect of state support for research and development]. Education and science in Russia: the state and development potential. 3, 553-589. (In Russ.)

6. Konysheva, L. K. \& Nazarov, D. M. (2011) Foundations of fuzzy set theory. Saint Petersburg, Piter. (In Russ.)

7. Kulagina, N. A. \& Kozlov, E. M. (2015) [Methodology of research of innovative potential in the development of regional programs of social and economic development]. University of Higher Education. XXI. 1, 31-40. (In Russ.) 
8. Kurchenkov, V. V. \& Deinega, V. G. (2013) [On the main approaches to the formation of a knowledgeintensive economy in modern Russia]. Business. Education. Law. 2 (23), 40-45. (In Russ.)

9. Latkin, A. P. \& Krivoshapov, V. G. (2018) [Modeling of the control of the integration of the higher education in the national innovation system]. Azimuth of scientific research: economics and administration. 7 (2), 181-186. (In Russ.)

10. Murzagalina, G. M. (2019) [University as a source of entrepreneurial culture]. Ekonomika i predprinimatelstvo. 6 (107), 729-732. (In Russ.)

11. Risin, I.E., Treshchevsky, Yu. I. \& Eitingon, V.N. (2014) [Key tasks of scientific and technological policy and approaches to their solution]. Journal of the Voronezh State University. Series: Economics and Management. 2, 134-138. (In Russ.)

12. Saenko, M. Y. (2018) [Innovative activity of universities in the development of Russian economy]. [Modern economic and information technologies].2,4-7. (In Russ.)

13. Serebryakova, N.A. \& Grishchenko, N.V. (2018) [Formation and development of innovative potential of region]. Economics. Innovations. Quality Management. 1 (22), 50a-52. (In Russ.)

14. Sirotkina, N. V., Polyakov, A. V. \& Goncharov, A. Y. (2015) [Innovation Environment of the Region: Formation and Development]. Voronezh, Scientific Book. 223. (In Russ.)
15. Surovitskaya, G. V. (2019) [Influence of flagship universities on development of regional economic and innovation systems]. University proceedings. Volga region. Social sciences. 2 (50), 200-209. (In Russ.)

16. Tabachnikova, M. B. (2016) Assessment of economic pessimism of institutional groups of the region. Region: systems, economy, management. 1 (32), 96-102. (In Russ.)

17. Frank E. V. (2019) [Modeling the process of formation and development of innovative potential of the flagship university of the region]. Moscow economic journal. 11, 79. (In Russ.)

18. Endovitsky, D. A., Tabachnikova, M. B. \& Treshchevsky, Yu. I. (2017) Analysis of the economic optimism of the institutional groups and socio-economic systems. Journal of Advanced Research in Law and Economics. VIII (6), 1745-1752.

19. Treshchevskiy, D. Y., Papin, S. N. \& Penina, E. O. (2019) Innovation Risks in the Region - Expert Analysis. In Proceedings of the 2nd International Conference on Economy, Management and Entrepreneurship (ICOEME 2019). Atlantis Press, 311-315.

20. Treshchevsky, Y., Nikitina, L., Litovkin, M. \& Mayorova, V. (2017) Results of Innovational Activities of Russian Regions in View of the Types of Economic Culture. In Russia and the European Union, Development and Perspectives. Contributions to Economics, 47-53.
Yuri I. Treschevsky, Doctor of Economics, Professor, Head of the Department of Economics and Organization Management, Voronezh State University, Voronezh, Russian Federation

E-mail: treshchevski@yandex.ru

ORCID: 0000-0002-0039-5060

Evgeny A. Rudnev, graduate student, Department of Economics and Organization Management, Voronezh State University, Voronezh, Russian Federation
E-mail: fopus@yandex.ru

ORCID: 0000-0002-3405-6227

Ivanov Ivan Sergeevich, student, Faculty of Economics, Voronezh State University, Voronezh, Russian Federation

E-mail: if.iwan2014@yandex.ru

ORCID: 0000-0002-9626-6924

Received 15.07.2020

Accepted 10.09.2020 